\title{
ステップ式最急傾斜法による分布定数系 最適問題の直接解法
}

\author{
金井喜 美 雄 \\ 防衛大学校航空工学教室 横須賀市走水 1-10-20 \\ (昭和 44 年 9 月 13 日 受付)
}

\section{Direct Method of the Optimal Control Problem of Distributed Parameter Systems Due to Stepwise Steepest Descent Method}

\author{
Kimio KanaI \\ (Dept. of Aeronautical Engineering, The Defense Academy, Yokosuka) \\ (Received September 13, 1969)
}

There are two kinds of algorithms for deriving the time-optimal control function. One is the indirect method which employs the necessary condition of optimal control such as the Pontryagin's maximum principle. The other is the direct method which does not employ such a necessary condition in solving the problem.

In this paper, an optimal control problem of metal heating process is solved numerically applying the Stepwise Steepest Descent Method, in which the proper value of stepsize is derived analytically by the minimizing performance criterion at each step.

In this method, the performance criterion value converges in about ten iterations. The convergence is compared with that in the Continuous Steepest Descent Method.

Although various methods have been proposed for optimizing distributed parameter systems, the authors proved that the Pontryagin's maximum principle is directly applicable in such optimization problems by introducing infinite-dimensional state variable equations. However, the convergence in the authors' previous method was not well established mathematically. As the present direct method determine the optimal control function without using the maximum principle, and moreover this numerical result agrees with the numerical solutions of the two point boundary value problem introducing infinite-dimensional equations, we may conclude that this indirect method produces results with acceptable engineering accuracy.

\section{1. まえがき}

さきに, 分布定数系の最適制御問題飞無限次元状態 方程式を導入し，ポントリアギンの最大原理を適用し て最適条件を求めると 2 点境界值問題は第 2 種フレド ホルム形積分方程式に亦着することを導き, フレドホ ルム形積分方程式解法のアルゴリズムを決定して具体 的に数值計算によって最適制御関数を求めた ${ }^{1)}$.また, 最適制御法則を決定するという立場からリカッチ解に 依存した閉ループ系の構成を解析し ${ }^{2)}$, 計算機を使用 してのリカッチ形偏微分方程式の近似解法を示し, 数 值計算を実行して近似最適制御系の構成, 評価関数の
収束を検討した ${ }^{3)}$.

本論文では以前にとりあげた時定数のある加熱炉で 金属片を加熱するという最適問題をステップ式最急傾 斜法によって最適条件を直接求めるときのアルゴリズ ムについて考察する.このとき, 各ステップの評価関 数値が最小になるような最適な歩みのとり方をシステ ムのウェイテング関数を用いて解析的に与光得ること を示し，そしてアルゴリズムを確立する。この手法を 具体的な数值計算に適用して最適制御関数を決定する. この結果を歩み係数が一定である連続式手法と比較し， さらに, 最大原理の必要条件を適用して得られる間接 法の結果とも比較して両手法の合理性を検討する. 


\section{2. 問 題の 記 述}

本論文でとりあげる問題は次のように記述されるも のとする．加熱プロセスの運動方程式は，

$$
\left.\begin{array}{c}
\frac{d X_{0}(\tau)}{d \tau}=-\gamma \cdot X_{0}(\tau)+u(\tau) \\
\frac{\partial X(\xi, \tau)}{\partial \tau}=\frac{\partial^{2} X(\xi, \tau)}{\partial \xi^{2}} \\
\left.\frac{\partial X(\xi, \tau)}{\partial \xi}\right|_{\xi=0}=\alpha\left[X(0, \tau)-X_{0}(\tau)\right] \\
\left.\frac{\partial X(\xi, \tau)}{\partial \xi}\right|_{\xi=1}=0
\end{array}\right\}
$$

で与光られる 1 。ここで， $X_{0}$ は加熱炬の雲囲気温度 をあらわし， $X(\xi, \tau)$ は金属片の温度， $u(\tau)$ は燃料 流量であり， $r, \alpha$ はそれぞれ炉放熱率，熱伝達率を あらわす．終端条件は，

$$
t_{f}: \text { 指定, } X_{0}\left(t_{f}\right), X\left(\xi, t_{f}\right): \text { 自由 }
$$

とする。 また，評価関数は次のようにとる.

$$
J=\frac{f}{2} \int_{0}^{1}\left[X^{*}(\xi)-X\left(\bar{\xi}, t_{f}\right)\right]^{2} d \xi+\frac{1}{2} \int_{0}^{t f} u^{2}(\tau) d \tau
$$

ここでは制御関数 (control sequence) を求めること が問題とされるから初期条件が指定されなければなら ない，初期条件は次のように扔くことにする。

$$
X_{0}(0)=0, X(\xi, 0)=0
$$

したがって, 本論文の問題の記述は評価関数 (5) 式 を最小にするような最適制御関数 $u(\tau)$ を決定する問 題であるといえる。

\section{3. 加熱プロセスのウエイテング関数}

最適問題のアルゴリズムを決定するために，まず， システムのウエイテング関数を求める必要がある．初 期条件 (6) 式を考虑して (2) 式をラプラス変換すると,

$$
\frac{\partial^{2} Z(\xi, s)}{\partial \xi^{2}}=s \cdot Z(\xi, s)
$$

となる.ここで， $s$ はラプラス演算子をあらわし， $Z$ は $Z(\xi, s)=\mathcal{L}[X(\xi, t)]$ を意味している.

(1)式抢よび境界条件 $(3)$ 式をラプラス変換すると,

$$
(s+\gamma) Z_{0}(s)=U(s)
$$

$$
\left.\begin{array}{l}
\left.\frac{\partial Z(\xi, s)}{\partial \xi}\right|_{\hat{\xi}=0}=\alpha\left[Z(0, s)-Z_{0}(s)\right] \\
\left.\frac{\partial Z(\xi, s)}{\partial \xi}\right|_{\xi=1}=0
\end{array}\right\}
$$

(7)式を乡について解くと一般解は次のようにかける。

$$
Z(\xi, s)=c_{1}(s) \cdot e \sqrt{s} \xi+c_{2}(s) \cdot e-\sqrt{s} \xi
$$

これから，

$$
\frac{\partial Z(\xi, s)}{\partial \xi}=\sqrt{s} \cdot\left\{c_{1}(s) \cdot e \overline{\sqrt{s} \xi}-c_{2}(s) \cdot e-\overline{\sqrt{s} \xi}\right\}
$$

となる。また（9) 式の第 1 式に（8)式の $Z_{0}$ を代入 すると，

$$
\left.\frac{\partial Z(\xi, s)}{\partial \xi}\right|_{\xi=0}=\alpha \cdot Z(0, s)-\frac{\alpha}{s+\gamma} \cdot U(s)
$$

とかきかえられる。したがって，(11)式の関係を用い ると，(9)，(12)式から，

$\left.\begin{array}{l}\sqrt{s}\left\{c_{1}(s)-c_{2}(s)\right\}=\alpha \cdot\left\{c_{1}(s)+c_{2}(s)\right\}-\frac{\alpha}{\alpha+s} U(s) \\ \sqrt{s} \cdot e \sqrt{s} \cdot c_{1}(s)-\sqrt{s} \cdot e-\sqrt{s} \cdot c_{2}(s)=0\end{array}\right\}$

(13)式から， $c_{1}, c_{2}$ を求めると,

$\left.\begin{array}{l}c_{1}(s)=\frac{e-\sqrt{s}}{\sqrt{s}\left(e^{\sqrt{s}}-e^{-\sqrt{s}}\right)+\alpha\left(e^{\sqrt{s}}+e^{-\sqrt{s}}\right)} \cdot \frac{\alpha}{s+\gamma} \cdot U(s) \\ c_{2}(s)=\frac{e^{\sqrt{s}}}{\sqrt{s}\left(e^{\sqrt{s}}-e^{-\sqrt{s}}\right)+\alpha\left(e^{\sqrt{s}}+e^{-\sqrt{s}}\right)} \cdot \frac{\alpha}{s+\gamma} \cdot U(s)\end{array}\right\}$

(14)式の関係を(10)式に代入して整とんすると，

$$
Z(\xi, s)=\frac{\cosh [(1-\xi) \sqrt{s}]}{\sqrt{s} \cdot \sinh \sqrt{s}+\alpha \cosh \sqrt{s}} \cdot \frac{\alpha}{s+r} \cdot U(s)
$$

と求まる. (15)式は時間領域に戻す必要があるが，コ ンボリュション積分として求めることが可能である.

いま，(15)式を次のように和く。

$$
Z(\xi, s)=W(\xi, s) \cdot U(s)
$$

ここで, $W(\xi, s)$ は次の関倸になっている.

$$
W(\xi, s)=\frac{\cosh [(1-\xi) \sqrt{s}]}{\sqrt{s} \sinh \sqrt{s}+\alpha \cdot \cosh \sqrt{s}} \cdot \frac{\alpha}{s+\gamma}
$$

つぎに，(16)式をラプラス逆変換すると，

$$
X(\xi, \tau)=\int_{t}^{\tau} W(\xi, \tau-\sigma) u(\sigma) \cdot d \sigma
$$

となる：ここに和いてシステムは偏微分方程式で記述 されてはいるが定数係数系であるからインパルス応答 は時間のインターバルのみを考虑すればよいことは明 らかである.したがって, ウェイテング関数 $W(\xi, \tau$ 一。) が求屯ると制御関数 $u(\tau)$ に対与る温度分布 $X(\xi, \tau)$ が決定できる. しかるに，ウエイテング関数 $W(\xi, \tau)$ を求めるには (17) 式をラプラス逆変換すれ ばよい。 $W(\xi, s)$ の極は無限個あり，次のようになる。

$$
s_{0}=-\gamma, s_{i}=-\beta_{i}{ }^{2} \quad(i=1,2 \cdots \cdots)
$$

ただし， $\beta_{i}$ は，

$$
\beta_{i} \cdot \tan \beta_{i}=\alpha
$$

なる超越方程式の実根である。いま, $W(\xi, s)$ の分母 を $H(s)$, 分子を $G(\xi, s)$ とおくと, $W(\xi, s)$ の逆変 換は次の公式を用いて求めることができる ${ }^{4)}$.

$$
W(\xi, \tau)=\mathcal{L}^{-1}\left[\frac{G(\xi, s)}{H(s)}\right]=\sum_{i=1}^{\infty} \frac{G\left(\xi, s_{i}\right)}{H^{\prime}\left(s_{i}\right)} e^{s_{i \tau}}
$$

すなわち， 


$$
\begin{aligned}
W(\xi, \tau) & =\sum_{i=1}^{\infty} \frac{2 \cos \left[(1-\xi) \beta_{i}\right]}{\left\{\left(\frac{1+\alpha}{\beta_{i}{ }^{2}}+\frac{1}{\alpha}\right) \cdot \cos \beta_{i}\right\} \cdot\left\{\gamma-\beta_{i}{ }^{2}\right\}} e^{-\beta_{i}{ }^{2} \tau} \\
& +\frac{\alpha \cos [(1-\xi) \sqrt{\gamma}]}{\alpha \cos \sqrt{\gamma}-\sqrt{\gamma} \cdot \sin \sqrt{\gamma}} \cdot e^{-r \tau}
\end{aligned}
$$

(22)式に拈いて $\beta_{i}$ は (20)式の根として無限個あるが 実際に数值計算をするのには最初の数項だけを考慮す れば十分である。

\section{4. 最急傾斜法による最適制御関数 を求めるアルゴリズム}

最急傾斜法によるアルゴリズムは次式で与兄られ $3^{5)}$.

$$
u_{p+1}(\tau)=u_{p}(\tau)-\left.K \cdot \frac{\partial J}{\partial u(\tau)}\right|_{u(\tau)=u p(\tau)}
$$

ここで, $u_{p}(\tau)$ は第 $p$ 番目の近似制御関数であり, $\partial J / \partial u(\tau)$ はこう配関数をあらわし，Kは歩みをあら わす定数である.

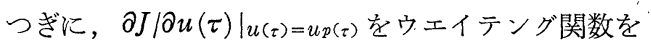
用いて計算することを考觉る。
一般に, 時刻 $\sigma$ 単位インパルススカが加えられた

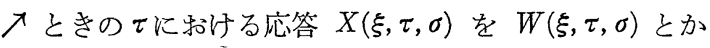
く. $W(\xi, \tau, \sigma)$ はインパルス応答であり, (18)式の関 係を満たしている。すなわち, 初期時刻を0とし, $\tau=t_{f}$ に和ける $X\left(\xi, t_{f}\right)$ を求めると,

$$
X\left(\xi, t_{f}\right)=\int_{0}^{t_{f}} W\left(\xi, t_{f}, \sigma\right) u(\sigma) d \sigma
$$

となり，この関係を(5)式に代入して $J$ 求めると，

$$
\begin{aligned}
J=\frac{f}{2} \int_{0}^{1}\left[x^{*}(\xi)-\int_{0}^{t_{f}} W\left(\xi, t_{f}, \sigma\right) u(\sigma) d \sigma\right]^{2} d \xi \\
+\frac{1}{2} \int_{0}^{t_{f}} u^{2}(\tau) d \tau
\end{aligned}
$$

こう配関数は次のように計算できる。 $u(\tau)$ の変分 を $\delta u(\tau)$ とし，これ伴う $J$ の 1 次增分を $\delta J$ と打 くとき, Jの 1 次増分は $\delta u$ とあるべクトルとの内積 の形であらわすことができる．このときの相手のべク

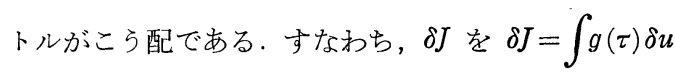
$(\tau) d t$ なる形であらわしたとき， $g(\tau)$ がこう配関数 オである.これらの関係を(25)式に適用すると，

$$
\begin{aligned}
J+\delta J= & \frac{f}{2} \int_{0}^{1}\left[X^{*}(\xi)-\int_{0}^{t f} W\left(\xi, t_{f}, \sigma\right)\{u(\sigma)+\delta u(\sigma)\} d \sigma\right]^{2} d \xi+\frac{1}{2} \int_{0}^{t f}\{u(\tau)+\delta u(\tau)\}^{2} d \tau \\
= & \frac{f}{2} \int_{0}^{1}\left[X^{*}(\xi)-\int_{0}^{t f} W\left(\xi, t_{f}, \sigma\right) u(\sigma) d \sigma\right]^{2} d \xi-f \cdot \int_{0}^{1}\left[\left\{X^{*}(\xi)-\int_{0}^{t f} W\left(\xi, t_{f}, \sigma\right) u(\sigma) d \sigma\right\}\right. \\
& \left.\times \int_{0}^{t f} W\left(\xi, t_{f}, \sigma\right) \delta u(\sigma) \cdot d \sigma\right] d \xi+\frac{f}{2}\left\{\int_{0}^{t f} W\left(\xi, t_{f}, \sigma\right) \delta u(\sigma) d \sigma\right\}^{2} d \xi \\
& +\frac{1}{2} \int_{0}^{t f} u^{2}(\tau) d \tau+\int_{0}^{t f} u(\tau) \cdot \delta u(\tau) \cdot d \tau+\frac{1}{2} \int_{0}^{t f}\{\delta u(\tau)\}^{2} d \tau
\end{aligned}
$$

となり，高次項を省略すると $\delta J$ は次のようになる。

$$
\delta J=f \cdot \int_{0}^{t_{f}}\left[\int_{0}^{1}\left\{\int_{0}^{t_{f}} W\left(\xi, t_{f}, \sigma\right) u(\sigma) d \sigma-X^{*}(\xi)\right\} W\left(\xi, t_{f}, \sigma\right) d \xi\right] \delta u \cdot d \sigma+\int_{0}^{t_{f}} u(\tau) \delta u(\tau) d \tau
$$

したがって，こう配関数 $g(\tau)=\partial J / \partial u(\tau)$ は,

$$
\frac{\partial J}{\partial u(\tau)}=f \cdot \int_{0}^{1}\left[\int_{0}^{t f} W\left(\xi, t_{f}, \sigma\right) u(\sigma) d \sigma-X^{*}(\xi)\right] W\left(\xi, t_{f}, \tau\right) d \xi+u(\tau)
$$

と求まる。いま，本論文で扱っているシステムは $W\left(\xi, t_{f}, \sigma\right)=W\left(\xi, t_{f}-\sigma\right)$ なる関係を満足するから $(28)$ 式は，

$$
\left.\frac{\partial J}{\partial u(\tau)}\right|_{u(\tau)=u p(\tau)}=f \cdot \int_{0}^{1}\left[\int_{0}^{t f} W\left(\xi, t_{f}-\sigma\right) u_{p}(\sigma) d \sigma\right] W\left(\xi, t_{f}-\tau\right) d \xi-f \cdot \int_{0}^{1} X *(\xi) \cdot W\left(\xi, t_{f}-\tau\right) d \xi+u_{p}(\tau)
$$

となる。(22)式の $W(\xi, \tau)$ を用いると数值計算が実行でき, 制御関数を決定することができる.

いま，簡単のために $X^{*}(\xi)$ 二一定とし，(22)式の $W(\xi, \tau)$ を用いて $(29)$ 式の積分を実行する。まず， (29) 式 の右辺第 2 項は,

$$
\begin{aligned}
& f \cdot \int_{0}^{1} X^{*}(\xi) \cdot W\left(\xi, t_{f}-\sigma\right) d \xi=f \cdot X^{*} \cdot \int_{0}^{1} W\left(\xi, t_{f}-\sigma\right) d \xi \\
& \quad=f \cdot X^{*}\left\{\sum_{i=1}^{\infty} \frac{2}{\left(\frac{1+\alpha}{\beta_{i}{ }^{2}}+\frac{1}{\alpha}\right) \cdot \cos \beta_{i} \cdot\left(\gamma-\beta_{i}{ }^{2}\right)} \cdot \frac{\sin \beta_{i}}{\beta_{i}} \cdot e^{-\beta_{i}\left(t_{f}-\tau\right)}+\frac{\alpha \cdot e^{-\gamma\left(t_{f}-\tau\right)}}{\alpha \cos \sqrt{\gamma}-\sqrt{\gamma} \sin \sqrt{\gamma}} \cdot \frac{\sin \sqrt{\gamma}}{\sqrt{\gamma}}\right\}
\end{aligned}
$$

(29)式の右辺第 1 項は,

$$
f \cdot \int_{0}^{1}\left[\int_{0}^{t_{f}} W\left(\xi, t_{f}-\sigma\right) u_{p}(\sigma) d \sigma\right] W\left(\xi, t_{f}-\sigma\right) d \xi=f \cdot \int_{0}^{1}\left[\sum_{i=1}^{\infty} \frac{2 \cos \left[(1-\xi) \beta_{i}\right]}{\left(\frac{1+\alpha}{\beta_{i}{ }^{2}}+\frac{1}{\alpha}\right) \cos \beta_{i} \cdot\left(\gamma-\beta_{i}{ }^{2}\right)}\right.
$$




$$
\begin{aligned}
& \left.\times \int_{0}^{t f} e^{-\beta_{i}{ }^{2}(t f-\sigma)} u_{p}(\sigma) d \sigma\right] \cdot\left[\sum_{i=1}^{\infty} \frac{2 \cos \left[(1-\xi) \beta_{i}\right]}{\left(\frac{1+\alpha}{\beta_{i}^{2}}+\frac{1}{\alpha}\right) \cos \beta_{i} \cdot\left(\gamma-\beta_{i}{ }^{2}\right)} \cdot e^{-\beta_{i}{ }^{2}(t f-\tau)}\right] d \xi \\
& +f \cdot \int_{0}^{1}\left[\sum_{i=1}^{\infty} \frac{2 \cos \left[(1-\xi) \beta_{i}\right]}{\left(\frac{1+\alpha}{\beta_{i}^{2}}+\frac{1}{\alpha}\right) \cos \beta_{i} \cdot\left(\gamma-\beta_{i}{ }^{2}\right)} \cdot e^{-\beta_{i}{ }^{2}(t f-\tau)}\right] \cdot\left[\frac{\alpha \cos [(1-\xi) \sqrt{\gamma}]}{\alpha \cos \sqrt{\gamma}-\sqrt{\gamma} \sin \sqrt{\gamma}} \cdot \int_{0}^{1} e^{-\gamma(t f-\sigma)} \cdot u_{p}(\sigma) d \sigma\right] d \xi \\
& +f \cdot \int_{0}^{1}\left[\sum_{i=1}^{\infty} \frac{2 \cos \left[(1-\xi) \beta_{i}\right]}{\left(\frac{1+\alpha}{\beta_{i}{ }^{2}}+\frac{1}{\alpha}\right) \cos \beta_{i} \cdot\left(\alpha-\beta_{i}{ }^{2}\right)} \cdot \int_{0}^{t f} e^{-\beta_{i}(t(t)-\sigma)} u_{p}(\sigma) d \sigma\right]\left[\frac{\alpha \cos [(1-\xi) \sqrt{\gamma}]}{\alpha \cos \sqrt{\gamma}-\sqrt{\gamma} \sin \sqrt{\gamma}} e^{-\gamma(t f-\tau)}\right] d \xi \\
& +f \cdot \int_{0}^{1}\left[\left(\frac{\alpha \cos [(1-\xi) \sqrt{\gamma}]}{\alpha \cos \sqrt{\gamma}-\sqrt{\gamma} \sin \sqrt{\gamma}}\right)^{2} \cdot \int_{0}^{t f} e^{-\gamma(t f-\sigma)} u_{p}(\sigma) d \sigma \cdot e^{-\gamma(t f-\tau)}\right] d \xi
\end{aligned}
$$

ここで，(31)式の右辺を個々に積分してから結合する。けっきょく，次のようなこう配関数が決定される.

$$
\begin{aligned}
& \frac{\partial J}{\partial u(\tau)} \underset{u(\tau)=u p(\tau)}{=} u_{p}(\tau)-f \cdot X^{*} \cdot\left\{\sum_{i=1}^{\infty} \frac{2 \sin \beta_{i} \cdot e^{-\beta_{i}{ }^{2}\left(t_{f}-\tau\right)}}{\left(\frac{1+\alpha}{\beta_{i}{ }^{2}}+\frac{1}{\alpha}\right) \cos \beta_{i}\left(\gamma-\beta_{i}{ }^{2}\right) \cdot \beta_{i}}+\frac{\alpha \sin \sqrt{\gamma} \cdot e^{-\gamma\left(t_{f}-\tau\right)}}{\sqrt{\gamma(\alpha \cos \sqrt{\gamma}-\sqrt{\gamma} \cdot \sin \sqrt{\gamma})}}\right\} \\
& +f \cdot \sum_{i=1}^{\infty} \cdot \int_{0}^{t f} e^{-\beta_{i}{ }^{2}(t f-\sigma)} \cdot u_{p}(\sigma) d \sigma \cdot\left[\left\{\frac{\sin \left(2 \beta_{i}\right)}{4 \beta_{i}}+\frac{1}{2}\right\} \frac{4 \cdot e^{-\beta_{i}{ }^{2}(t f-\tau)}}{\left\{\left(\frac{1+\alpha}{\beta_{i}{ }^{2}}+\frac{1}{\alpha}\right) \cos \beta_{i} \cdot\left(\gamma-\beta_{i}{ }^{2}\right)\right\}^{2}}\right. \\
& \left.+\frac{\alpha \cdot e^{-\gamma(t f-\tau)}}{\left\{\left(\frac{1+\alpha}{\beta_{i}{ }^{2}}+\frac{1}{\alpha}\right) \operatorname{sos} \beta_{i} \cdot\left(\gamma-\beta_{i}{ }^{2}\right)\right\}(\alpha \cos \sqrt{\gamma}-\sqrt{\gamma} \sin \sqrt{\gamma})} \cdot\left\{\frac{\sin \left(\beta_{i}+\sqrt{\gamma}\right)}{\beta_{i}+\sqrt{\gamma}}+\frac{\sin \left(\beta_{i}-\sqrt{\gamma}\right)}{\beta_{i}-\sqrt{\gamma}}\right\}\right]
\end{aligned}
$$

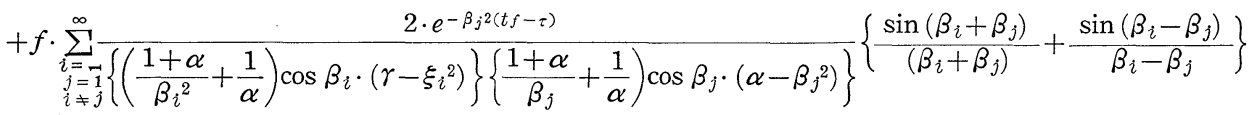

$$
\begin{aligned}
& \times \int_{0}^{t f} e^{-\beta_{i}{ }^{2}\left(t_{f}-\sigma\right)} \cdot u_{p}(\sigma) d \sigma+f \cdot \int_{0}^{t f} e^{-\gamma\left(t_{f}-\sigma\right)} \cdot u_{p}(\sigma) d \sigma\left[\frac{\alpha^{2} \cdot e^{-\gamma\left(t_{f}-\tau\right)}}{(\alpha \cos \sqrt{\gamma}-\sqrt{\gamma} \sin \sqrt{\gamma})^{2}}\left(\frac{\sin (2 \sqrt{\gamma})}{4 \sqrt{\gamma}}+\frac{1}{2}\right)\right. \\
& \left.+\sum_{i=1}^{\infty} \frac{\alpha \cdot e^{-\beta_{i}{ }^{2}\left(t_{f}-\tau\right)}}{\left\{\left(\frac{1+\alpha}{\beta_{i}{ }^{2}}+\frac{1}{\alpha}\right) \cos \beta_{i} \cdot\left(\gamma-\beta_{i}{ }^{2}\right)\right\} \cdot(\alpha \cos \sqrt{\gamma}-\sqrt{\gamma} \sin \sqrt{\gamma})}\left\{\frac{\sin \left(\beta_{i}+\sqrt{\gamma}\right)}{\beta_{i}+\sqrt{\gamma}}+\frac{\sin \left(\beta_{i}-\sqrt{\gamma}\right)}{\beta_{i}-\sqrt{\gamma}}\right\}\right]
\end{aligned}
$$

この関係式を(23)式に代入して第 $p$ 番目の $u(\tau)$ を適当炕与兄ると, 歩及係数 $K$ を試行錯誤的に与えることによ らてくり返し計算で近似解を求めることができる。しかし，Kの与方によっては計算時間が非常にながくなり， 収れんがしにくくなる．特に連続式最急傾斜法ではこの傾向が強くなり，実用的ではない，比例傾斜あゆ及手法 を用いてるくり返し計算の途中で歩みの大きさをか光てらまく収束するような $K$ をきめるのは容易でない，第 $p$ 番目の $u(\tau)$ が与兄られると, $\partial J /\left.\partial u(\tau)\right|_{u(\tau)=u p(\tau)}$ が計算でき，Kをきめると次のステップの $u_{p+1}(\tau)$ が求まる から $K$ を最適に選んでおけげ $p+1$ 段の評価関数值を最小にできる。すなわち，第 $p$ 番目の制御関数が与えら机 ると $J_{p+1}$ を最小にするような $K$ をきめることができる。評価関数 $(5)$ 式に (18)，(23) 式の関係を代入すると $J_{p+1}$ は次のようになる.

$$
J_{p+1}=\frac{f}{2} \cdot \int_{0}^{1}\left[X *(\xi)-\int_{0}^{t f} W\left(\xi, t_{f}-\sigma\right)\left\{u_{p}(\sigma)-K \cdot \frac{\partial J}{\partial u_{p}}(\sigma)\right\} d \sigma\right]^{2} d \xi+\frac{1}{2} \int_{0}^{t_{f}}\left\{u_{p}(\tau)-K \cdot \frac{\partial J}{\partial u_{p}}(\tau)\right\}^{2} d \tau
$$

(33)式は未知係数 $K$ みの関数である. (33)式を展開して $K$ に関して整とんすると,

$$
\begin{aligned}
& J_{p+1}=\frac{K^{2}}{2} \cdot\left[\int_{0}^{t f}\left(\frac{\partial J}{\partial u_{p}}\right)^{2} d \tau+f \cdot \int_{0}^{1}\left(\int_{0}^{t f} W \cdot \frac{\partial J}{\partial u_{p}} \cdot d \sigma\right)^{2} d \xi\right]-K \cdot\left[\int_{0}^{t f} u_{p} \cdot \frac{\partial J}{\partial u_{p}} d \tau\right. \\
& \quad-f \cdot \int_{0}^{1}\left(X^{*}-\int_{0}^{t f} W \cdot u_{p} d \sigma\right)\left(\int_{0}^{t f} W \cdot \frac{\partial J}{\partial u_{p}} \cdot d \sigma\right) d \xi+\frac{f}{2} \cdot \int_{0}^{1}\left(X^{*}-\int_{0}^{t f} W \cdot u_{p} \cdot d \sigma\right)^{2} d \xi+\frac{1}{2} \int_{0}^{t_{f}} u_{p}{ }^{2} d \tau
\end{aligned}
$$

となる.ここで, $J_{p+1}$ は $K$ に関して 2 次式となり， $K^{2}$ の係数が正であるから最小值が存在する. $J_{p+1}$ を最小に するような最適值 $K_{0}$ の值を求めると次の関係式が得られる.

$$
K_{0}=\frac{\int_{0}^{t_{f}} u_{p}(\tau) \cdot \frac{\partial J}{\partial u_{p}}(\tau) d \tau-f \cdot \int_{0}^{1}\left\{\left(X^{*}(\xi)-\int_{0}^{t_{f}} W\left(\xi, t_{f}-\sigma\right) u_{p}(\sigma) d \sigma\right)\left(\int_{0}^{t_{f}} W\left(\xi, t_{f}-\sigma\right) \frac{\partial J}{\partial u_{p}}(\sigma) d \sigma\right)\right\} d \xi}{\int_{0}^{t_{f}}\left\{\frac{\partial J}{\partial u_{p}}(\tau)\right\}^{2} d \tau+f \cdot \int_{0}^{1}\left\{\int_{0}^{t_{f}} W\left(\xi, t_{f}-\sigma\right) \frac{\partial J}{\partial u_{p}}(\sigma) d \sigma\right\}^{2} d \xi}
$$

(35)式の $K_{0}$ が各ステップに括ける最適な歩み倸数を与兄る関係式である.したがって，こう配関数 (32) 式と最 適なあゆみ係数 (35) 式とを用いて (23) 式をくり返し計算すると制御関数が求まる. 同時に, 各ステップの評価関 
数值を計算し，その值が収束したところで計算をうち きれば近似ではあるが最適制御関数が決定でき，その ときの最適温度分布も計算できる。

\section{5. 数 值 計 算}

具体的な加熱プロセスとして次の数值計算を行なう ことにする。

$$
\left\{\begin{array}{l}
X^{*}=0.2 \quad f=1.0 \times 10^{4} \\
t_{f}=0.4 \quad \gamma=25, \quad \alpha=10 \\
\beta_{i} \tan \beta_{i}=10 \quad i=1, \cdots, 6
\end{array}\right.
$$

次に, $p=1$ に和ける制御関数はどらいら関数形にな うているのかわからないので次のように仮定する。

$$
\left.u(\tau)\right|_{p=1}=0
$$

(37)式の初期条件から計算を開妶し，各ステップの制 御関数を計算すると Fig. 1 の結果を得る.こう配関 数を計算するさいの数值積分はニュートン・コーツの

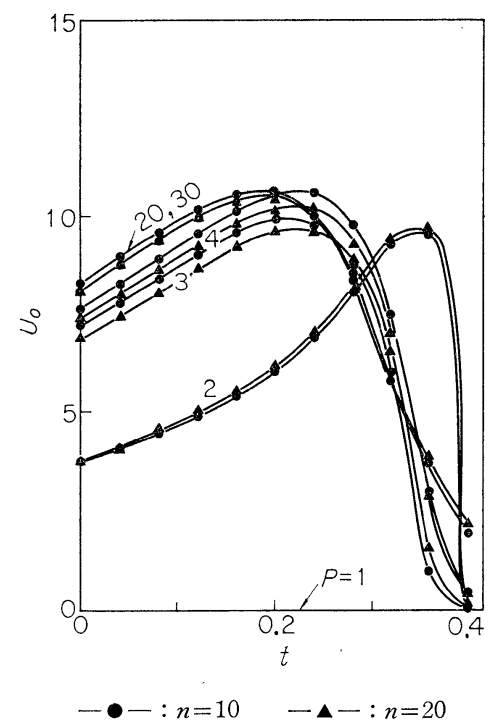

Fig. 1 Calculation of optimal control

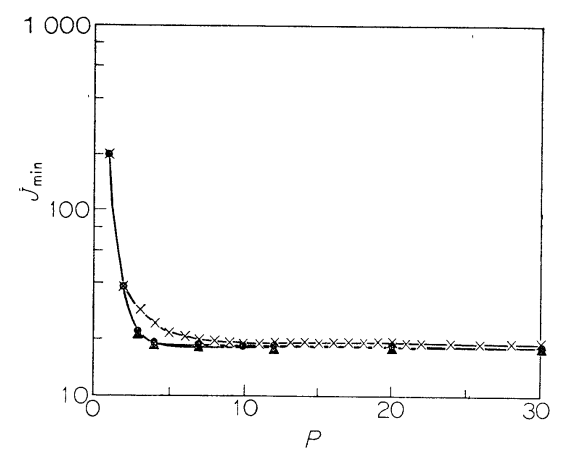

- - : stepwise steepest descent method $(n=10)$

- $\mathbf{\Delta -}$ : stepwise steepest descent method $(n=20)$

$-\times-$ : continuous steepest descent method

Fig. 2 Performance criterion values
近似式を用い, 分割の数を $n=10,20$ そついて実行 した. $p=10$ までは各ステップごとに大きな変動がみ られるが，これ以後のくり返し計算ではほとんど差異 があらわれなくなる。ささらに, 数值積分の分割では $n=10$ で十分であることも明らかである.

つぎに，ステップごとの評価関数值を計算したのが Fig. 2 であるが, 図から明らかのように $p=6 \sim 10$ くらいで収束する. 同じ数值について連続式最急傾斜 法で計算した結果を同時にプロットしているが本論文 の手法と比較できる. ここで, 連続式最急傾斜法の歩 及係数の大きさはステップ式手法に和将る $p=1$ の最 適值を用いている. $p=30$ に和ける評価関数值をそれ ぞれについて求めると,

$$
J_{30}=\left\{\begin{array}{l}
18.554 \text { (ステップ式, } n=10) \\
18.523 \text { (ステップ式, } n=20) \\
18.563 \text { (連続式, } n=10) \\
19.985^{1)} \text { (間接法) }
\end{array}\right.
$$

となり，汪とんど大差のない結果になっている。しか し, 罒から明らかのように収束に要するステップ 数 （所要時間）が連続式にくらべて著しく改善されてい る.ここで, 間接法とは途中で最大原理の必要条件を 適用し, フレドホルム形積分方程式を解いたアルゴリ ズムのことである.

金属片の温度分布は (24)式の関係式から計算できる。 すなわち, Fig. 1 で得られた $u(\tau)$ の各ステップの 值に対して(24)式をニュートン・コーツの近似式を用 いて数值積分を実行する (Fig. 3)。ここでも2 種類

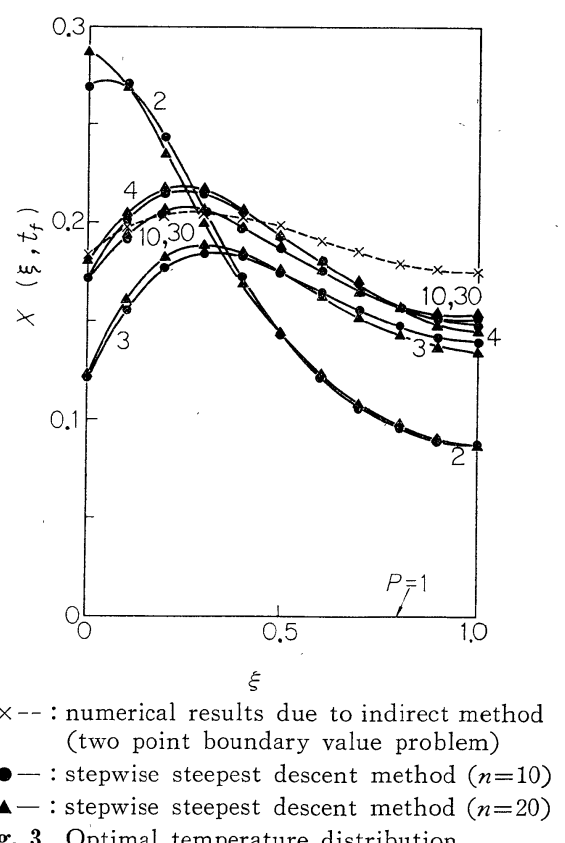

Fig. 3 Optimal temperature distribution 


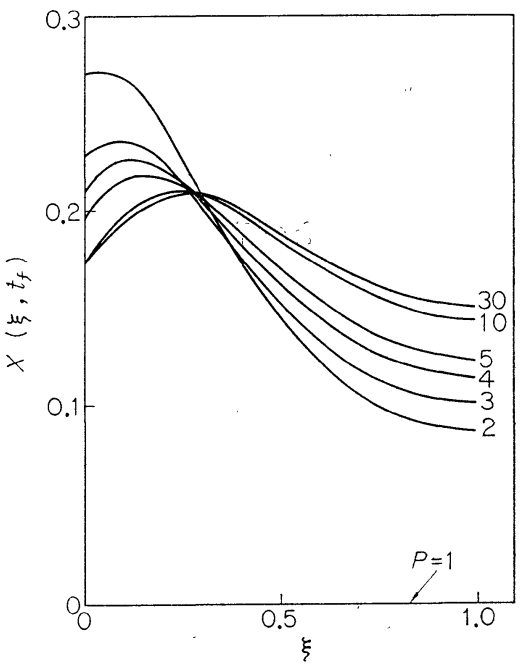

Fig. 4 Optimal temperature distribution applying continuous steepest descent method

の分割の仕方で計算したが，結果は注とんど一致して いることがわかる。また， $p=10$ を越えると収束して しまっている様子も明らかである. 図中の点線であら わした曲線は同じ加熱プロセスの最適問題汇無限次元 状態方程式を導入して最大原理を適用し，最適条件と して第 2 種フレドホルム形積分方程式を解いた結果 ${ }^{1)}$ から得られた最適な温度分布をあらわしている. 途中 の数值積分の近似の相異から発生する両手法の誤差を 考虑すればほぼ妥当な結果が得られたとみなせる.

Fig. 4 は連続式最急傾斜法 $(K=0.054221$ に固定) によって計算した温度分布の結果をプロットしたもの である. Fig. 3 と Fig. 4 との結果を比較することに よって最適な歩み係数を選んだことによる効果が $p=$ 3〜4ぐらいに顕著にあらわれていることが明らかで ある。

さらに，計算時間の比較に関してはステップ式手法 の活うが連続式手法にくらべて必ずしも収束が速いと はい党ない点に注意すべきである。なぜならば，各ス テップごとに最適な歩み係数を計算する作業が加わる のでとれだけ時間が長くなるので単にステップの回数 だけの比較では緟密ではない。しかし, 本論文では両 手法の比較のために第1 ステップの歩み係数を共通に 最適值をとった関係で連続式手法もかなりよい収束が 得られたが，あまり妥当でない係数を選んだどしたら 連続式手法は収束までにかなり時間が長くなり,さら に，収束しない場合すら起こり得る。

以上の結果より本論文の手法によって求まった最適 制御関数はかなり精度の高いものが得られたとみなせ る.間接法との比較で精度をあげるためには無限個の 和を有限個（i=6）で近似したが，さらにこの個数を ふやす必要があるように思われる。ただ，間接法では フレドホルム形積分方程式を近似計算して $X\left(\xi, t_{f}\right)$ を求め, しかるのちに $u_{\mathrm{opt}}(\tau)$ を最適制御条件式か らきめているのに反し, 直接法では解析的なウェイテ ング関数形を求め，こら配関数をウェイテング関数で あらわれて数值積分を実行し, しかるのちに, ウェイ テング関数を用いたコンボリュション積分を近似計算 して $X\left(\xi, t_{f}\right)$ を求めているので敩密に比較するのは かなり複雑であるように思われる。

\section{6. あとがき}

最適制御関数を求めるアルゴリズムには，ポントリ アギンの最大原理のよらな最適制御の必要条件を適用 したら兊で求める間接法と, そのような必要条件を求 めないで直接的に最適制御関数を求める直接法とがあ るが，本論文では分布定数系の代表例とし・て加熱プロ セスの最適問題をとりあげ，ステップ式最急傾斜法を 適用して直接法によって最適制御関数を決定する方法 を示し, 計算機を使用して具体的な数值計算を実行し た。

従来，分布定数系の最適制御問題に関しては種々の 手法が提案されてきたが，筆者らは無限次元状態方程 式を導入することによってポントリアギンの最大原理 が分布定数系に対しても直接的に適用できることを示 し，その最適条件を導いた ${ }^{1)}$. しかし，無限次元状態 方程式の導入は極限操作に预いて数学的厳密性に久け るものであった．本論文のアルゴリズムは直接法であ るから途中で最大原理を補助手段として適用しないで 最適制御関数が決定できるのはもちろんであるが，こ の数值解が無限次元状態方程式の導入により得られた 2 点境界值問題の数値計算の結果とほぽ一致したとい らことは, 無限次元状態方程式の導入による筆者らの 手法の正当性が実証できたとみなしてさしつかえな い.

また，本論文では同一の計算式をくり返し使用する 逐次近似的な方法でディジタル計算機を用いたが，10 ステップくらいで収束したといら結果から判断して, さらに，具体的な問題には最大原理の適用自体が非常 に困難になる場合が多い点を考慮すると，本論文のよ らな直接法によるアルゴリズムの利用価值は高いもの であると考兄られる。

本論文では最適制御の時間関数を求めたので開ルー プ制御になっている. 1 回だけの $u_{\mathrm{opt}}(\tau)$ を求めた だけでは単にプログラム制御をしただけで完全に開ル ープ制御であるが，もし無限回のくり返しで $u_{\mathrm{opt}}(\tau)$ 
を求めな打すと仮定すれば optimal control law に もとずいて構成されたシステムと同じ動作をすること になる．最近の計算機の発達を考学るとがなり速く $u_{\mathrm{opt}}(\tau)$ を求めな扔すことができるので，それだけよ い制御ができることになる.

終わりに，筆者が名古屋大学大学院工学研究科博士 課程在学中に御指導いただいた市川邦彦教授, 日ごろ 御指導いただいている航空工学教室塚原鶴夫教授，ま たディジタル計算機で御指導いただいた高尾吉郎教授, 高尾ぶじ江講師の皆様に心から感謝します。
参考文 献

1）市川・金井：ポソトリアギン最大原理の分布定数系最 適制御への適用, 電気学会誌, 89-973, 1949/1958 (1969-10)

2）市川・金井：分布定数系の最適制御シンセシス，日本 機械学会論文集, 36-284，565/577 (1970-4)

3）金井：ある分布定数系の最適フィードバック制御とリ カッチ形偏微分方程式の近似解法, 計測自動制御学会 論交集, 6-1，45/53 (1970-2)

4) E. H. Beckenbach : Modern Mathematics for the Engineer, McGraw-Hill (1961)

5）市川・田村：こう配法による最適制御問題の解法，計 測と制御, 8-11，761/771 (1969-11) 